\title{
Design and Testing of an integrated Ground Handler Working Position
}

\author{
Joern Jakobi \\ Human Factors Department \\ +495312952536 \\ joern.jakobi@dlr.de
}

\author{
Karsten Straube \\ Operations Control Dep. \\ +495312952946 \\ karsten.straube@dlr.de \\ DLR - Institute of Flight Guidance \\ Lilienthalplatz 7 \\ 38108 Braunschweig, Germany
}

\author{
Steffen Loth \\ Operations Control Dep. \\ +495312952811 \\ steffen.loth@dlr.de
}

\begin{abstract}
After air traffic controllers and pilots had been supplied with new surveillance and planning support tools in the airport environment the last decade, airport ground handlers are still suffering out-of-date technology and thus, nowadays, frequently cause bottlenecks for efficient surface operations. The dispatcher and baggage drivers lack a full traffic pictures, have to compile needed information from difficultly accessible sources and are bound to a sequential radio communication. By that reason a humancentered concept for ground handlers was designed, implemented and tested at Hamburg Airport. Dispatcher and driver were provided with the complete traffic situation in real time, data link communication and an integrated human- machine interface (HMI) providing all needed information at one gaze and intuitive interactions to assign tasks to the driver by one click only. The concept design was much appreciated by the dispatchers.
\end{abstract}

\section{Keywords}

Ground handler, integrated working position, design, dispatcher, Hamburg Airport, DLR, Airport2030

\section{INTRODUCTION}

At an airport these days many different service providers are involved to handle aircraft from touch down via turn around back to take-off. To keep this complex process working, each service provider must perform highly efficient and they must work hand in hand, since the chain is only that strong as its weakest link. Whilst air traffic and apron/ramp controllers as well as pilots have been provided with better surveillance technology and effective decision support tools (e.g. A-SMGCS / ASD-X, departure planning, or electronic flight bags (EFB) in the cockpit) the last decade, ground handler dispatcher and driver still work like they did decades ago. They usually do not have an outof-the-window view on the ramp area neither they are provided with a traffic situation display, they do not get planning support, they work at fragmented working positions where they have to compile the information needed and frequently can take ad-hoc decisions only instead of a pro-active planning. Addressing these disadvantages a project called 'Airport2030' was launched in 2009 to generate a concept that provides solutions to overcome those drawbacks and enable ground handler acting more efficient. In a first step a task analysis was conducted to learn about the used technology and current working procedure, about their weaknesses and to discuss opportunities for improvements. This paper in hand describes the realization of those opportunities in a concept for an integrated dispatcher working position, its transfer into an experimental prototype and the evaluation results of a shadow-mode test campaign at Hamburg Airport.

\section{BACKGROUND}

In 2009 the German Federal Ministry of Education and Research (BMBF) funded the project 'Airport2030'. Hamburg Airport was selected by BMBF as it is the world's third largest network of civil aviation industry. 'Airport2030' brought together a variety of different research topics in the areas of airport management and flight control. For a period of five years research organizations, universities and industrial partners worked together on a comprehensive study of airport processes, new technical approaches and modelling capabilities for airport operations. Four technical work packages have been set up to cover the main aspects for future development: 'Passenger', 'Aircraft', 'Airport Access', and 'Operations'. Within the 'Operations' work package the central elements of the project were the optimization of the control of ground handling services and traffic on the apron, as well as the improvement of safety and efficiency of the entire airport operation. Besides the conceptual work, a system development and tests in a real environment at Hamburg Airport was the main goal of the project.

The European Organisation for the Safety of Air Navigation (Eurocontrol) uses an early Demonstration and Evaluation platform (eDEP) for development and evaluation of new concepts. As the eDEP already provides some technical implementation of considered functionalities, cooperation with them was agreed. Because of the high flexibility of the eDEP platform the ground handling working position concept could be used to technically implement the new functions [2]. 


\section{HUMAN-CENTERED DESIGN OF AN INTEGRATED GROUND HANDLER WORKING POSITION}

\section{Task Analysis}

A task analysis at the ground handler dispatcher working position revealed that current working procedures are often manual with very limited automation support [4]. The dispatcher at Hamburg Airport is situated in a control room without an out-of-the-window view. In general s/he coordinates around 10 vehicle drivers by allocating tasks to them to either pick up trollies, loaded with baggage from just arrived aircraft, to bring it to the baggage belts inside the airport building, or, to pick up loaded trollies from the baggage claim to an aircraft for an outbound flight. Within a turn-around phase of a flight an inbound flight changes to an outbound flight. The aircraft itself remains the same of course but its call sign and operational status change. The dispatcher always aims for to combine outbound and inbound tasks for one driver only, saying, a driver who brings baggage to an outbound aircraft in a follow-on task picks up inbound baggage to bring it to the airport building. To initiate the allocation of such tasks the dispatcher uses different triggers: For inbound flights the dispatcher receives digital 'ten miles out', 'landing' and 'on-block' reports, for outbound flights s/he receives digital 'baggage ready’ reports from the baggage claim. To avoid inefficient waiting times for the drivers the dispatcher always attempts to provide a most efficient timing of the task allocation. However, without an out of the window view or without any information where the vehicles actually are and what the actual status of the aircraft is, this is a very challenging mental task and frequently guess-work and semi-efficient thumb rules apply to allocate tasks to the best suitable drivers right in time [5] [6].

Further on, operating the technical system by the dispatcher to extract information from the local flight plan server, flight status information, duty times of the drivers, baggage ready times and baggage amount, type and positioning of the freight requires many mouse clicks and necessary information is hidden in sub-menus and spread over four displays and several input devices.

And last, even when voice communication with the drivers via radio, particular with non-nominal tasks or problems, is very efficient, radio is sequential only, error prone and time consuming when exchanging routine information. For all those reasons an integrated working position with a complete traffic picture, decision support tools including data link communication were proposed to alleviate the dispatcher tasks and to enable the dispatcher to work more efficient.

\section{Concept Design}

Reflecting the results of the task analysis the integration of all relevant information for the ground handling dispatcher and all needed interaction in one single HMI was the overall aim of the concept. Further on, familiar interaction processes from working positions for tower and apron controllers were analyzed and taken into account. All this resulted in the concept idea to provide the dispatcher with a visualization of the complete traffic situation and the implementation of data link connection for all routine communication between vehicle driver, dispatcher and baggage claim manager to fade out drawbacks of voice communication via radio telephony $(\mathrm{R} / \mathrm{T})$ [8]. Basic visual components of the HMI are the representation of the traffic situation, a list of all inbound flights, including their connecting outbound flights, a list of all drivers/vehicles including their operational status (free, in progress, not available), and the most important innovation: An interactive pictograph for each aircraft parking position (cf. Figure 3).

The visualization of the complete traffic situation includes the position and identification of all aircraft and all ground handlers' owned vehicles on the entire movement area (cf. Figure 1).

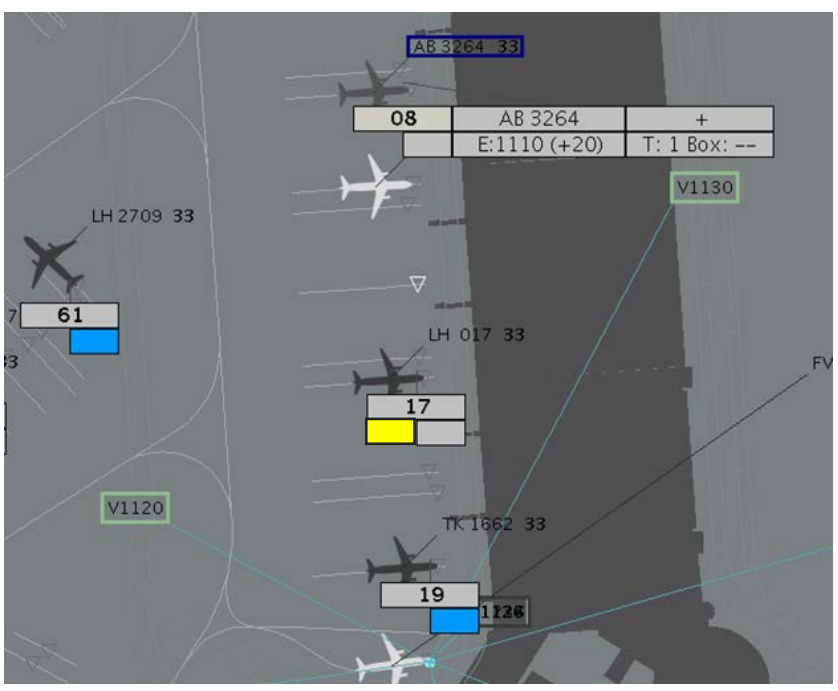

\section{Figure 1 Traffic Situation Display}

All aircraft are displayed not only when moving at the airport but also when standing on the parking position. The real time position and identification information of the aircraft is fed by A-SMGCS surface radar sensors. As aircraft identification (ID) is no longer receivable after final parking when aircraft transponder has been switched off by the pilot, the systems creates a dummy aircraft symbol indicating that the position is occupied by an aircraft. All needed flight status information is accessible via the parking position pictograph (see Figure 3 and Figure 4).

The operational state of a vehicle is color-coded through the vehicle label and the vehicle status list (see Figure 2). Green indicates that the vehicle is ready for use, a white flashing shows the dispatcher that a task has been allocated but not confirmed yet by the driver, a steady white indicates the driver's acceptance and that a task is being conducted. Red represents any disturbance (car break, rejection, etc.) that has to be solved via voice communication, if needed. The aircraft symbols are also color-coded to inform about an inbound or outbound flight. 


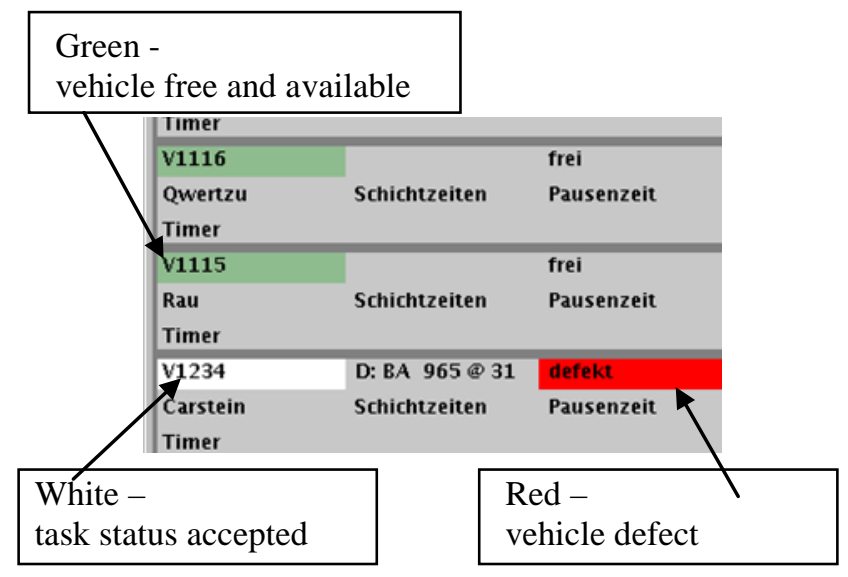

Figure 2 Vehicle status list

By a mouse-over function the aircraft label extends, showing all needed flight plan information. In addition to that, the respective flight in the flight list is highlighted including the connected outbound flight, and, when a task had already been allocated to a vehicle, also the respected vehicle label is lighted up. Further on, flights on final approach path can be seen in a separate window providing information on the arrival sequence. That will help the dispatcher to better plan the sequence of required unload/load tasks more in advance. All this essential information was hardly available in the regular working position, rather could only be attained by effortful explorations.

As already mentioned above, core of the integrated working position is the interactive pictograph for each aircraft parking position (see Figure 3).

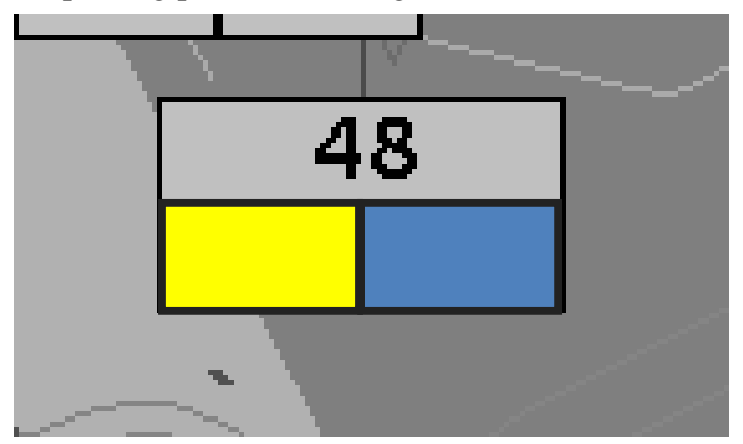

Figure 3 Pictograph for each aircraft parking position

There is one pictograph for each parking position. The central upper field indicates the parking position number (the stand or gate). The lower left field provides information of the inbound flight, the lower right field for outbound flights. Via color coding different flight status: The whole pictograph usually is masked but appears right in time when the flight is discovered by the approach radar, the center upper field turns magenta when the arrival flight is ten miles out. The 'ten-miles-out' report usually is the trigger for the dispatcher to send a driver to the respective parking position. Therefore, as a reminder to the dispatcher the inbound field of the pictograph turns yellow when the flight is landed and no task has been allocated yet to a baggage/freight unloading vehicle. For the outbound case a blue color indicates that baggage is ready to be transferred from the baggage claims to the aircraft. By a 'mouse over' function the pictograph extends and the dispatcher is provided with all information s/he needs to operate a flight (see Figure 4).

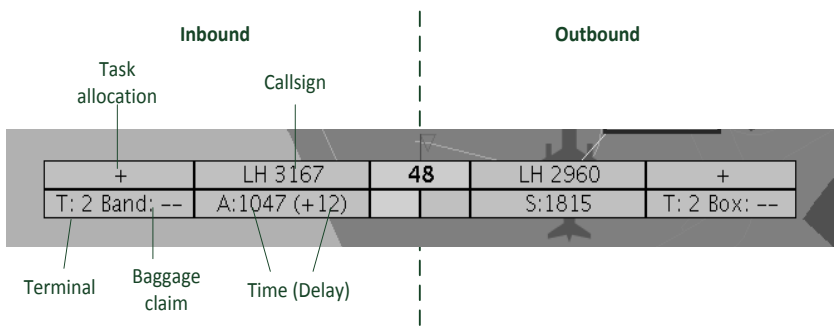

Figure 4 Extended pictograph for each aircraft parking position

On the left hand side of the pictograph the dispatcher gets all inbound information, on the right hand side all outbound information, e.g. the inbound and outbound call sign, estimated, scheduled and actual arrival and departure times, destinations where to bring or pick up baggage/freight.

The dispatcher can also assign vehicles to this flight by clicking on the + symbol. If so, another input mask appears which lists all available vehicles and also highlights the best choice for that flight in bold letters (see Figure 5) ${ }^{1}$.

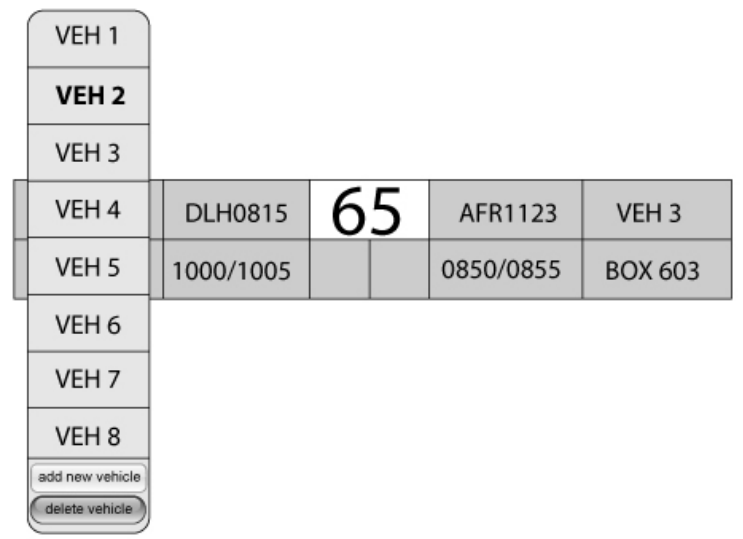

Figure 5 Vehicle list linked to the parking position pictograph

Via click in the pictograph the dispatcher gets additional information on the aircraft registration, the number of passengers, baggage and fright and the load plan (see Figure 6).

\footnotetext{
${ }^{1}$ The best choice is determined by an optimizing module running constantly in the background. After clicking " + ” the algorithm gets all positions of currently available vehicles and returns the vehicle which is nearest to the starting point of the task (baggage claim or aircraft parking position (compare also [7]).
} 


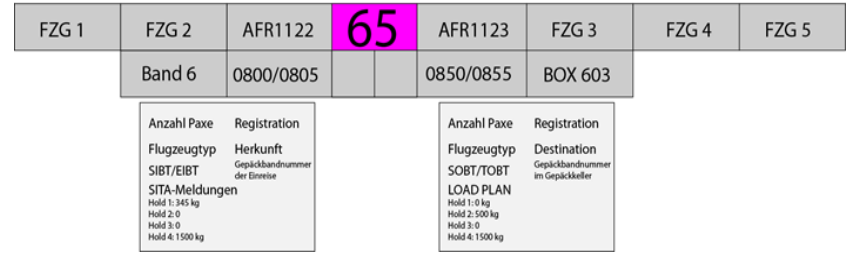

Figure 6 Extended pictograph - additional flight information

When the dispatcher has allocated a task to a vehicle, the vehicle number will then be displayed in the respective box of the extended pictograph. The dispatcher can also drag any vehicle (preferably a green label) displayed on the traffic situation display and drop it on the left or right lower field of the pictograph. Dropping the vehicle label to the left field will allocate the vehicle to the inbound flight (unload), on the right field to the outbound flight (load). When the label is dropped, a task with all information the driver needs is automatically transferred to the vehicle onboard unit via data link. The pictograph field then is white flashing as long as the driver does not confirm the receipt of the task and accepts to conduct it. When done so, the color turns into a steady white. After accomplishment of the task the driver on her/his onboard unit presses the executed button and the driver label and the pictograph field turns back to green, indicating ready for further use.

In some cases more than one vehicle needs to be assigned to a flight. With larger aircraft the number of baggage is higher and one vehicle cannot take all trollies at the same time. Once a dispatcher has assigned the first vehicle, the pictograph extend again by an additional column with a "+”. Now the dispatcher can repeat the allocation process by clicking the “+” again and select a further vehicle.

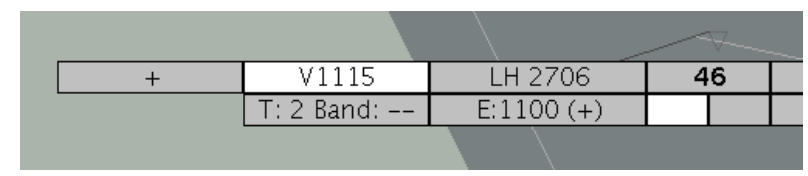

Figure 7 Extended pictograph - task allocated

The color coding of each vehicle box is according to the status of the task described above. The color coding of the main pictograph changes back to green, when all tasks of all vehicles have been processed and finished.

\section{EVALUATION METHOD \\ Objectives}

The overall evaluation objective was the proof of the technical and operational feasibility of the concept. For that purpose the prototype was integrated in the real operational environment and tested in shadow-mode. Advantage of shadow-mode trials in the field is that the new concept in real life faces real traffic scenarios, real technical interfaces and real operational problems. Disadvantage is that the traffic scenario cannot be planned nor repeated to handle an experimental baseline condition [3]. As key indicators the dispatchers' subjective judgments on their felt situational awareness (SA) and on the usability of and acceptance to the new working position were assessed. The formulated hypotheses postulated an over-average operator's attitude to all three indicators.

\section{Environment and set up}

By cooperation between the German air navigation service provider DFS, Hamburg Airport and the German Aerospace Center DLR, a test platform for research and development in the field of Air Traffic Management and Airport Operation is operated. This Airport Research and Innovation Facility was used to develop the new integrated dispatcher working position and to get all needed operational data. The self-contained research network has direct access to real live data from the operational ASMGCS (movement of aircraft) and the airport database (flight information). As the access is only unidirectional, no interference with the operational systems is possible. In addition to the normal research network a virtual wireless network segment is available for communication throughout the whole airport movement area. The following figure illustrates the relations of the different components and there data flow between them (see Figure 8). Positions of the equipped vehicles are calculated by GPS and sent via the wireless network to the situation server. Together with the positions of the aircraft an overall traffic situation was set up and sent to the dispatcher working position and the vehicle onboard systems under test. In parallel, status information from the vehicles and flight information from the airport database are processed and correlated with the traffic. As mobile client, dispatcher working position and ground handling server are based on the same programming platform, an event based communication service is used for the exchange of task information between dispatcher and vehicle driver.

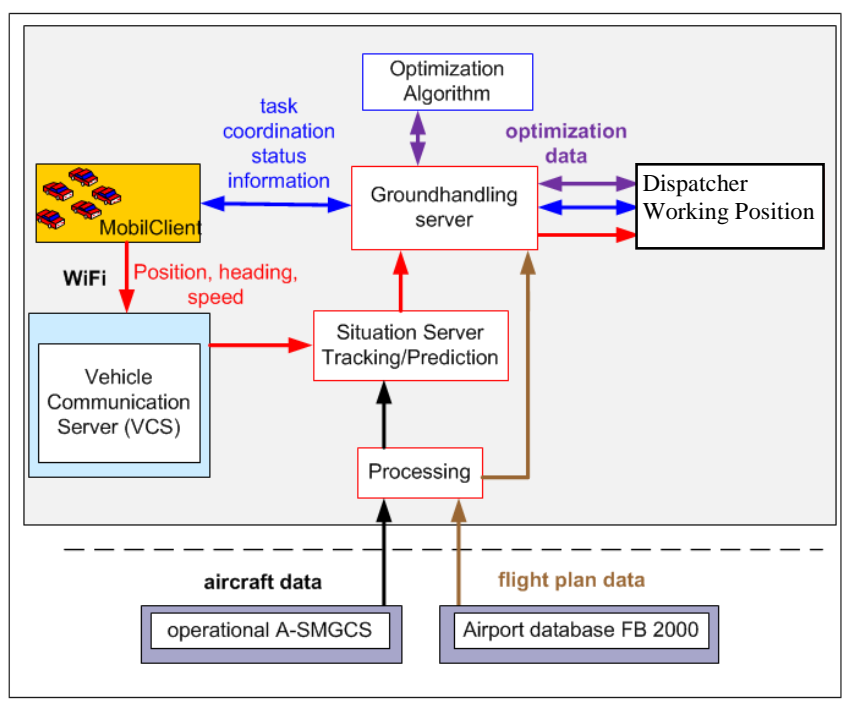

Figure 8 Components and data flow of the Vehicles Management System 


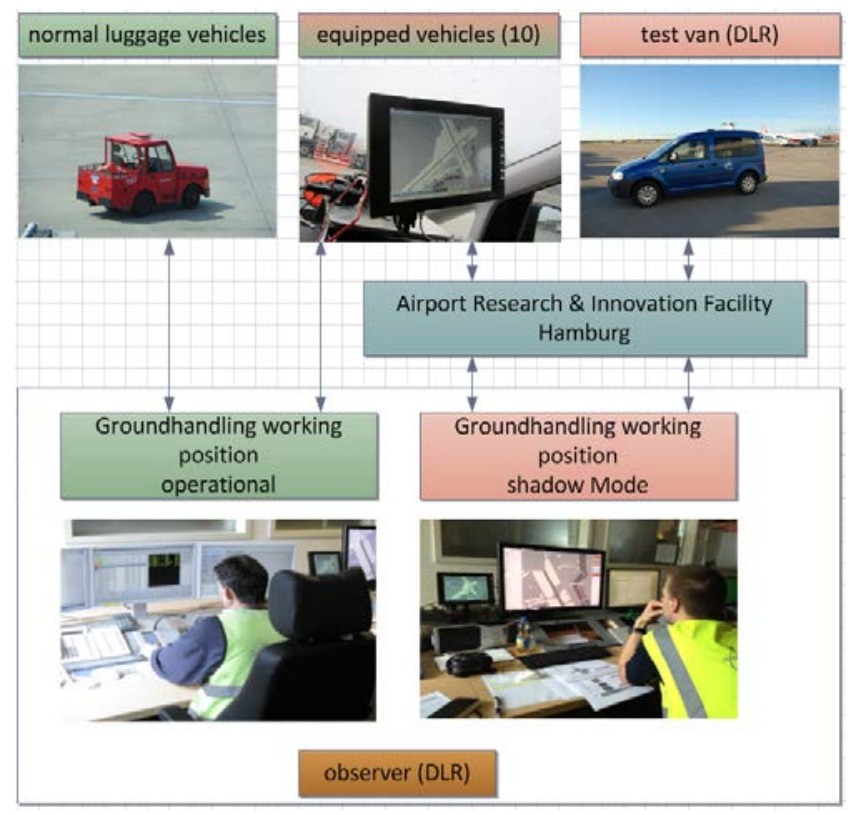

Figure 9 Test facilities and their concatenation

Data from the operational systems were processed and integrated in the vehicle management system. For the field trials ten baggage vehicles were equipped with an onboard system (touch display, netbook-pc, power supply and antennas). A dedicated DLR test van was also equipped for system checks and special training operations. The newly developed integrated ground handling working position was set up next to the current operational dispatcher working position and directly connected to the research network (see Figure 9).

\section{Test subjects}

There is only a limited amount of dispatchers with a ground handler at Hamburg Airport. Three of them could be gained as test subjects. All three were male and experienced. All had worked more than 10 years as a dispatcher.

\section{Experimental procedure}

As already discussed above, a shadow-mode field trial, and thus a quasi-experimental design (without a baseline) was chosen. For the measurement of the indicators standardized questionnaires were applied. They were developed by EUROCONTROL in their 'Solutions for HumanAutomation Partnerships in European ATM' (SHAPE) project [1]. Those questionnaires were specially designed to assess situational awareness and usability when implementing higher automation levels in a human machine interaction. Acceptance was measured by a tailormade questionnaire with closed questions, dedicated to the concept design elements. To each item test subjects were also encouraged to provide further comments. In advance of each test run the test subject became a detailed briefing to the new working position and conducted a training run. This familiarization phase was followed by the actual test run that lasted 60 minutes. During this test run the regular operational dispatcher was sitting right beside the test subject and worked at the regular position. From this position s/he assigned tasks to the baggage vehicle drivers by voice via radio. The test subject dispatcher worked in parallel with the new integrated working position, monitored all tasks assignments and did the same assignment via the new working position, independent whether the vehicle was equipped with a data link or not. When a vehicle was data link equipped the task appeared on the driver's onboard unit, the driver could answer to it, which was shown again on the dispatcher's display. If it was not equipped the test subject dispatcher could manually set the task status in accordance to the voice feedback, which was given to the operational dispatcher. An observer always sat behind the test subjects compiling all irregularities and comments by the test subject. The test run itself was pursued by a debriefing session to fill in the standardized SHAPE questionnaires as well as the acceptance questionnaire and, by an interview, to compile the general assessment of the new working position through the test subjects.

\section{RESULTS \& DISCUSSION}

With the Situational awareness for SHAPE Questionnaire (SASHA) the situational awareness (SA) of the test subjects was measured post hoc. As expected, all three test subjects (TS) revealed an over-averaged SA (see Figure 10): TS1 $=3.83$ (63.9\%), TS2 $=5.67(94.4 \%)$, TS3 $=4.00$ (66.7\%).

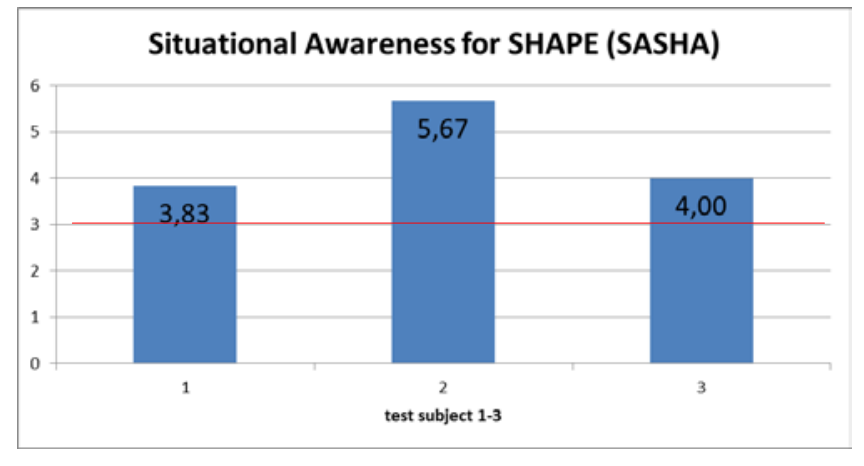

Expected mean value $=3$

\section{Figure 10 Situational awareness of each test subject}

3.50 (58.0\%), 2.67 (44.4\%) and 2.17 (36.1\%) are the test subjects' measured values out of the SHAPE Automation Trust Index (SATI) questionnaire. Only one test subjects is convinced of an overall usability. This results is rather disappointing one a first view, but with a detailed review to the six SATI items it is recognizable that items referring to utility, comprehensibility and safety are rated over-averaged by all three test subjects. On the other hand robustness, precision and reliability are rated under-averaged (see Figure 11). This result pattern is rather well pursuable: The concept of an integrated working position was realized in an experimental prototype that did not undergo a quality check like an industrial site acceptance test. Therefore the technical performance related to robustness, preciseness and reliability was relatively poor as assessed by the test 
subjects. In contrast and in expectation of the investigators the concept idea itself was understood and appreciated by the test subjects (compare results in Figure 11).

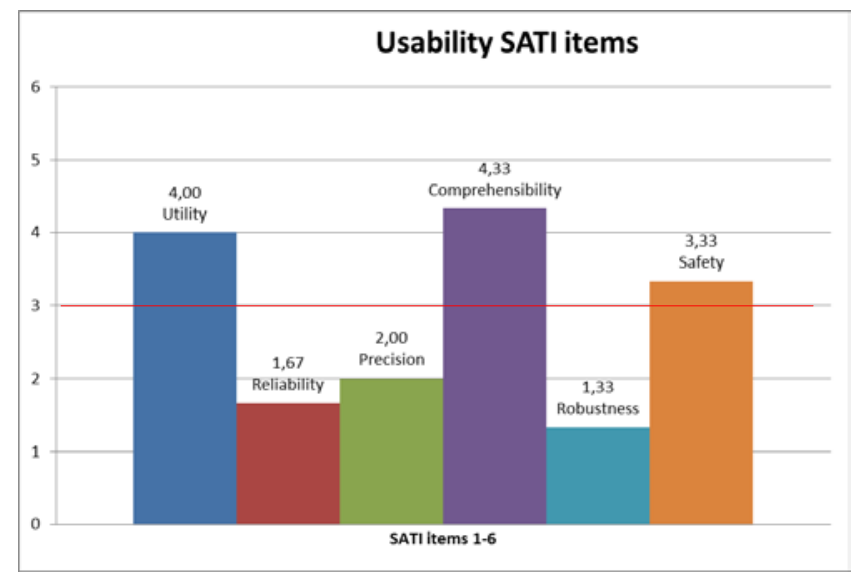

Expected mean value $=3.0$

\section{Figure 11 SHAPE Automation Trust Index (SATI)}

For the assessment of the overall acceptance of the concept a dedicated 21 item questionnaire was developed. The 21 items were to be answered on a Likert scale from $0=$ strongly disagree through $5=$ strongly agree. The items loaded on five categories: $S A$, workload (WL), training (T), design (D), and data link (DL) (see Table 1).

\begin{tabular}{|l|l|}
\hline 1_SA & $\begin{array}{l}\text { I was presented with the current traffic situation } \\
\text { helping me to localize and identify all relevant } \\
\text { aircraft and vehicle. }\end{array}$ \\
\hline 2_SA & I had access to all relevant information. \\
\hline 3_SA & $\begin{array}{l}\text { The integrated working position helped me to } \\
\text { foresee the traffic situation in the near future. }\end{array}$ \\
\hline 4_WL & $\begin{array}{l}\text { The display of the traffic situation with all } \\
\text { movements helped me to reduce my workload in } \\
\text { heavy task load times. }\end{array}$ \\
\hline 5_WL & $\begin{array}{l}\text { The traffic situation display of all vehicles helped } \\
\text { me to reduce my workload in heavy task load } \\
\text { times. }\end{array}$ \\
\hline 6_WL & $\begin{array}{l}\text { Working on that integrated working position in } \\
\text { general would reduce my workload in heavy task } \\
\text { load times. }\end{array}$ \\
\hline 7_T & $\begin{array}{l}\text { A professional familiarization with the integrated } \\
\text { working position does not require any extensive } \\
\text { training. }\end{array}$ \\
\hline The processing of tasks via the pictograph: \\
\hline 8_D & seems to be very intuitive, \\
\hline 9_D & seems to be very error tolerant, \\
\hline 10_D & would make my working more efficient. \\
\hline 11_D & $\begin{array}{l}\text { The display of all states of a task to be processed } \\
\text { via the pictograph is very helpful. }\end{array}$ \\
\hline
\end{tabular}

\begin{tabular}{|l|l|}
\hline 12_D & $\begin{array}{l}\text { The color coding of the pictograph for the } \\
\text { different states is very intuitive. }\end{array}$ \\
\hline 13_D & $\begin{array}{l}\text { Using an aircraft symbol at the parking position } \\
\text { indicating if a position is free or occupied is very } \\
\text { helpful. }\end{array}$ \\
\hline 14_D & $\begin{array}{l}\text { I only want to see the pictographs I am } \\
\text { responsible for. }\end{array}$ \\
\hline 15_D & $\begin{array}{l}\text { Pictographs shall only be activated when related } \\
\text { tasks are to be processed within a time horizon of } \\
\text { +30min / - 5min. }\end{array}$ \\
\hline 16_D & $\begin{array}{l}\text { That I can overwrite all states manually seems to } \\
\text { be reasonable. }\end{array}$ \\
\hline 17_D & $\begin{array}{l}\text { The flight plan list contains all information I need } \\
\text { for my work. }\end{array}$ \\
\hline 18_D & $\begin{array}{l}\text { If I could process tasks directly within a flight } \\
\text { plan would help me. }\end{array}$ \\
\hline 19_D & $\begin{array}{l}\text { The interactive concatenation of pictograph and } \\
\text { flight plan list seems to be very helpful. }\end{array}$ \\
\hline 20_D & $\begin{array}{l}\text { The interactive concatenation of arrival and } \\
\text { departure flight within the flight plan list and the } \\
\text { respective pictograph seems to be very helpful. }\end{array}$ \\
\hline 21_DL & $\begin{array}{l}\text { The task allocation to the driver and their } \\
\text { feedback via data link seems to be very helpful. }\end{array}$ \\
\hline
\end{tabular}

\section{Table 1 Items of the acceptance questionnaire}

When reviewing the results, test subject 2 reports acceptances values by nearly $100 \%$ (TS2 $=4.62(92.4 \%)$ ). The other two subjects were more hesitant and report more average values: TS1 $=3.29(65.7 \%)$ and TS3 $=2.76$ (55.2\%) (see Figure 12).

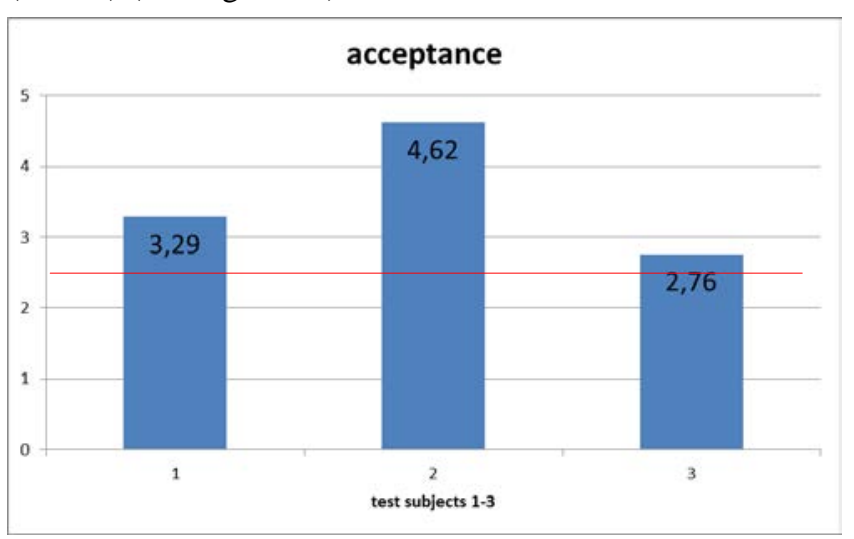

Expected mean value $=2.5$

Figure 12 Acceptance of each test subject - tailor-made acceptance questionnaire

Surveying the mean values of the categories a positive picture reveals: Except of category training 2.0, wherein the test subject rejected a limited need for training, all categories showed over- average values. Particularly with the category design (mean value $=3.8$ ), which reflects 13 statements to the concept design of the new working 
positions, the test subjects granted high acceptance scores (see Figure 13 for all results).

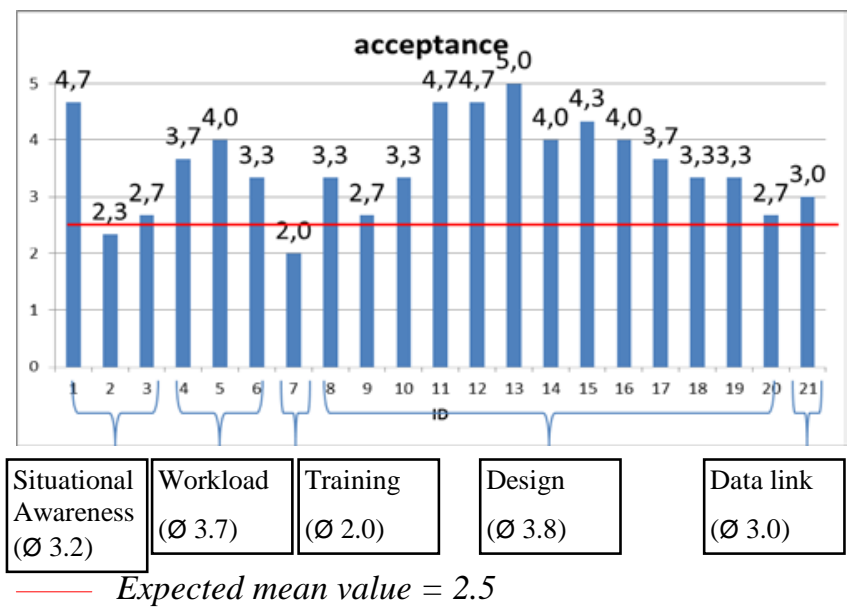

Figure 13 Average acceptance for each item and category

\section{SUMMARY AND CONCLUSIONS}

Due to a small sample size the test power is rather limited and thus an inference analysis was abandoned and all results were represented descriptively. However, as the sample size is rather identical with the entire population of Hamburg ground handler dispatchers the external validity is rather high and results could be used to derive meaningful trends. It can be stated that the concept design for an integrated dispatcher working position is usable and acceptable and enables the user to gain an over-average situational awareness picture. Negative feedback was given to the technical reliability and robustness of the system, which can be explained that an experimental prototype in a real operational environment was set up and used. Technical problems like data link losses or missing flight plan data occurred occasionally. But those technical problems can easily be solved in further iterative technical tests, at last, when a prototype is transferred into an industrial product. As a result, the technical feasibility could not be proven yet but as long as the concept design is appreciated by the users, research has gone in the right direction. Unfortunately, the local manufacturer for dispatcher working positions was not partner in the Airport2030 project that a direct transfer to the industry could not been settled yet, but is anticipated for the near future.

\section{ACKNOWLEDGMENTS}

The project Airport2030 was funded by the the German Federal Ministry of Education and Research (BMBF). We would like to thank all partners for the fruitful collaboration. Many thanks to the Airport Hamburg GmbH and their affiliated companies for the support in the technical realization of the vehicle management system and the execution of the field trials. Special thanks to all dispatchers and drivers for taking part in the test runs and their feedback and comments. Further on we would like to thank Eurocontrol for providing the early Evaluation and Demonstration Platform (eDEP) as a base for the developments.

\section{REFERENCES}

1. Dehn, D., Assessing the Impact of Automation on the Air Traffic Controller: The SHAPE Questionnaires, in Air Traffic Control Quarterly, Vol 16(2), 127-146, 2008.

2. Eurocontrol, Early Evaluation and Demonstration Platform, http://www.eurocontrol.int/eec/public/standard_page/E RS_edep.html

3. European Commission \& EUROCONTROL, European Operational Concept Validation Methodology - EOCVM, Version 3, Brussels, Belgium, February 2010.

4. Jakobi, J.; Airport2030 - Ergebnisbericht - Ground Handler Arbeitsplatz, Version 1.0, Braunschweig, 2013

5. Flughafen Hamburg GmbH, Verkehrsregeln und Zulassungsbestimmungen für das Betriebsgelände, Stand Juli 2005

6. Fuge, A und Höfer, B „Der kritische Pfad Bodenabfertigung aus der Sicht der Bodenverkehrsdienste der Hamburg Airport Gruppe“, Hamburg, 2001.

7. Kuhn, K. et al., Airport Service Vehicle Scheduling, in Air Traffic Control Quarterly, Vol 18(1), 63-83, 2010.

8. Straube, K.; Airport2030 - Operationelles Konzept für einen Ground Handling-Disponenten im Jahr 2015, Version 2, Braunschweig, 2012 